\title{
Academic Cheating is Contagious: the Influence of the Presence of Others on Honesty. a Study Report
}

\author{
Agata Błachnio*, Malgorzata Weremko
}

Department of Emotion and Motivation Psychology, The John Paul II Catholic University of Lublin, Poland, Lublin, 20-950, Poland

\begin{abstract}
The main aim of the study was to investigate the determinants of academic dishonesty. Its scope was limited to the specific kind of dishonest behavior which is commonly present among students: the phenomenon of academic dishonesty, manifested in cheating (colloquially: cribbing) on tests, exams, etc. The author predicted that an agreement between each participant and the experimenter would induce participants to remain honest. The research was conducted in the form of a laboratory experiment. The results indicated that the presence of the experimenter's confederate was significant. Participants cheated more often when the other person cheated than they did when writing the test individually. However, it turned out that the agreement had no influence on the participants' behavior. Another research problem concerned the influence of personality determinants on dishonesty. The effect of self-esteem and attitude towards disloyalty on disloyal behavior was investigated. The main results showed that the participants who cheated had lower self-esteem in comparison with those who did not cheat. As regards attitude towards disloyalty, it was found that loyalty had a low value for the participants who cheated, while non-cheaters valued it highly.
\end{abstract}

Keywords Cheating, Academic Honesty, Self-Esteem, Disloyalty

\section{Introduction}

The aim of the present paper is to establish the factors that may influence dishonest behavior in schools. An attempt was made at experimental verification of the hypothesis that the presence of another cheating person increases dishonest behaviors and that a request for honesty reduces them.

Academic cheating is a phenomenon present at all levels of education in Poland and treated with considerable leniency. In contrast, plagiarism or intellectual property theft are socially stigmatized. The media publicize cases of scientists guilty of plagiarism, but a cheating student does not attract the attention of journalists. In his book The cheating culture, Callahan[1] writes about an epidemic of cheating which exists in all societies. Cheating at schools is part of the mass culture of cheating. Let us therefore look at this disgraceful phenomenon that has attracted the interest of researchers, chiefly American, for years. First studies on academic cheating were conducted in 1964 by Bill Bowers. His study revealed that three fourths of the respondents had cheated at least once in their lives. A replica of that study, 33 years later, revealed an increase of school dishonesty, particularly during tests and exams[2].

The literature mentions several types of academic

* Corresponding author:

gatta@kul.pl (Agata Błachnio)

Published online at http://journal.sapub.org/ijap

Copyright (C) 2011 Scientific \& Academic Publishing. All Rights Reserved dishonesty, namely: copying from someone else's test (or letting others copy from one's own), copying assignments or papers with the authors' consent, paraphrasing fragments of text without footnoting, citing without acknowledging the source, copying texts from the Internet, signing works that one did not make any contribution to, providing others with answers for tests $[3,4]$.

It is difficult to say exactly how cheaters differ from non-cheaters. Numerous studies indicate that men use crib sheets more often than women do[cf. 3, 5, 6]. One of the explanations of this difference is that women, more often than men, are internally motivated to study. Studies have also appeared suggesting the prevalence of women or no gender differences among academic cheaters[6]. Moreover, the two genders differ in their reactions to the introduction of punishment for academic cheating. A considerable decrease of this kind of dishonest behavior has been found in women warned about the punishment. Differences in dishonesty have also been reported that depend on the subject that exams concern. It transpires that women more frequently cheated on maths exams while male cheaters dominated on language exams[3]. The study of Newstead[5] reveals that men cheat more often because studying is not an aim in itself for them. Men study in order to avoid taking up work or for other social reasons. They tend to be result-oriented whereas women tend to be learning-oriented, and this could explain gender differences in dishonest academic behavior.

There is no agreement, either, as regards the direction of differences in academic cheating between individuals at 
various ages. More cheating is present in high schools and colleges than in elementary schools. Authors ascribe this to the fact that education is more skills-oriented and grade-oriented in higher grades than it is in lower grades. Other studies show, however, that the amount of cheating decreases with age. Results also emerge showing that cheating is different at different levels of education and, what follows, that it changes with age. For example, school students copy assignments or cheat on exams more often than college students. The reasons behind cheating remain the same, however[6].

The presence of the phenomenon of academic dishonesty is undeniable in all cultures; what differs is its scope as well as the attitude it encounters and the penalties it results in. Numerous study reports indicate cultural differences. German students cheat less, view this problem as less serious, and judge cheating more leniently than their peers from the United States. Other studies reveal that Americans cheat more often than Australians, which is accounted for by the stronger emphasis placed on achievements and grades in the USA[6]. Unlike Americans, Russians have a more lenient attitude towards cheating, not regarding such behavior as dishonest[3]. Studies on Singapore students show that they judge cheating as morally ambivalent and tend to tolerate such behavior in their colleagues. They judge cheating or other kinds of academic dishonesty as unfair but not harmful enough to be stopped[7]. The individualism or collectivism of a society considerably affects its attitude towards academic cheating. In collectivistic societies, collaborative cheating such as copying from others with mutual agreement occurs more frequently than in individualistic societies $[8,9]$.

It is beyond doubt that not every person cheats, which provokes the interesting question of what differentiates those who succumb to the temptation of cheating from those who do not. One of these traits is self-efficacy - the belief that one is able to achieve a goal on their own. Individuals with low self-efficacy and less self-confident ones cheat more often than those with high self-efficacy. There have also been suggestions that cheating is positively related to impulsive decision-making and adventurousness[6]. Morevover, Whiley's studies[10] indicate that those students who aim high and experience strong pressure to succeed cheat more often than their colleagues who do not strive for victory so intensely. A Turkish study show that students who use the self-handicapping strategy to a greater extent and are more effective cheat more often[8]. Finn \& Frone [11] observed that cheating could be related to learning achievements and identification with school. The students with rather poor achievements cheat less often if they have strong identification with school; by contrast, if their identification is low they decide to cheat more frequently. De Bruin \& Rudnick[12] demonstrated the positive association of academic dishonesty with excitement seeking (excitement seeking) and its negative association with conscientiousness. Not very conscientious students are less self-disciplined and may put less effort in preparation for an exam, which is why they resort to prohibited behavior - cheating; if, additionally, they have a high level of excitement seeking and assess the risk involved in dishonesty as low, then they will probably decide to cheat. Marsden, Carroll, \& Neill[13] investigated three kinds of academic dishonesty: cheating, plagiarizing, and fabrication. Their study reveals that individuals dishonest at school had low self-efficacy, were not learning-oriented, and had low grades. Grade-orientedness was strongly associated with cheating and plagiarizing. The literature also connects academic dishonesty with heroism. It has been demonstrated that individuals with a high level of heroism are honest. Heroism correlates positively with sense of guilt in a situation of academic dishonesty and with lack of justification for misconduct[14]. Heroic individuals declare that if they cheated they would feel guilty, and that they have no intention to cheat in the future[15]. Less self-confident individuals and those with lower self-efficacy cheat more often, which may suggest that students with lower self-esteem will more often decide to engage in misconduct at school or in college. It also turns out that the student's morality is strongly related to cheating[6].The main aim of the study is to check whether request for honesty and the presence of another cheating person during tests affects cheating behavior. Błachnio's study[16] shows that request for loyalty has a significant influence on the subsequent behavior of participants. It is possible to refer to self-presentation theory here[cf. 17], according to which man cares about making a good impression on others; consequently, we may assume that a person asked for loyalty will behave loyally in order to make a good impression - that is, to be judged as a loyal person. We therefore assumed the following: A request not to cheat results in fewer people in the group cheating.

Based on social learning theory, according to which imitation is connected with the adoption of other people's behavior, it is believed that this happens as an automatic process. It may be assumed that the presence of another cheating person will evoke similar behavior among the individuals writing a test and that they will cheat more often than they do when writing alone.

The study conducted by Aronson \& Mettee[18] showed that individuals with low self-esteem more often commit immoral acts than individuals with high self-esteem, which means that the level of self-esteem determines cheating: those with low self-esteem cheat more often than those with high self-esteem. Let us also see if the decision on whether or not to cheat may depend on the professed moral values[cf. 19]; we assume that the individuals who cheat do not value loyalty.

\section{Procedure and Methods}

In order to verify the hypotheses, an experiment was carried out in a laboratory with a two-way mirror, where the behavior of the participant could be observed. In the room to which the participants were invited there was a desk and two chairs. Various books were lying on the desk, including a spelling dictionary, a foreign words dictionary, and a thesaurus. Above the desk, a request was hung not to take the 
aids out of the laboratory. Participants were also informed that the mess, with the books lying there, was due renovation works the laboratory. The experimenter invited one participant at a time. Each participant was informed that they were taking part in a university contest organized by the Student Governments Association of Lublin Universities. The aim of the study as conveyed to the participants was to assess the students' knowledge of orthography and to measure their social attitudes. In the first part of the study participants wrote a spelling test, and in the second part they filled questionnaires. One set of experimental conditions involved a request not to cheat and the other did not include this request. The experimenter would leave for a moment under the pretext of a phone call. When writing the test, some of the participants were accompanied by a confederate of the experimenter, who was using the dictionaries lying on the desk, and other participants were not accompanied by anyone. Additionally, the participants filled in two questionnaires.

One of them was Rosenberg's Self-Esteem Scale (SES), measuring the attitude to one's own worth[20]. The scale consists of 10 items. Answers were given on a scale from 1 to 4, where 1 meant "I strongly agree" and 4 meant "I strongly disagree." The overall score of 10 indicated low self-esteem, while 40 revealed high self-esteem. Cronbach's alpha coefficient for the scale is 0.82 .

The other questionnaire was Błachnio's[19] Attitudes towards Disloyalty Scale (LOJAL), measuring attitudes towards disloyalty. The scale includes 25 items, representing two factors, named "loyalty" and "justification of disloyalty." The loyalty subscale measures the extent to which an individual regards loyalty as a matter of honor, whereas the justification of disloyalty subscale measures the extent to which a person allows betrayal by maintaining it to be unavoidable because, in a way, inherent in human nature. The participants were supposed to respond to statements on a 5-point scale; the more points, the more a given statement was true for the participant. Cronbach's alpha was 0.76 for subscale 1 and 0.84 for subscale 2 .
The study was conducted on 60 students, randomly divided between 4 experimental conditions, 15 individuals in each group.

\section{Results}

In order to answer the question of whether a request for honesty and the presence of another person influence academic cheating, a log-linear analysis was performed with the aim of uncovering the relations between these factors and the frequency of cheating. Log-linear analysis tests the influence of various factors and their interactions. The results obtained are shown in Table 1. A step on the way to understanding the relations between cheating and request for honesty or confederate's presence was the $\mathrm{k}$-factor interactions test and partial and marginal association models. The test revealed one significant interaction. It was observed that cheating was influenced by the presence of the experimenter's confederate, who was cheating; no such effect was found in the case of request for honesty.

A statistically significant relation was found between the variables of cheating and confederate's presence $(\chi 2(60)=$ 12.79 , at $\mathrm{p}=0.01$ ). Table 2 shows the numbers of participants who cheated and those who did not cheat in the presence or absence of a confederate.

As we can see (Table 2), participants cheated more often in the presence of the confederate (21 people) than they did when writing the test alone (7 people). When writing alone, participants remained loyal, whereas only 9 people resisted the temptation of cheating in the presence of another cheating person.

The next issue under consideration was whether cheaters and non-cheaters differ in their self-esteem and attitudes towards disloyalty. In order to answer this question, one-factor analysis of variance (ANOVA) was performed (Table 3).

Table 1. Tests of marginal and partial association

\begin{tabular}{|c|c|c|c|c|c|}
\hline Effect & $\begin{array}{c}\text { Degrees } \\
\text { of freedom }\end{array}$ & $\begin{array}{c}\text { Partial association } \\
\chi^{2}\end{array}$ & $\mathrm{p}$ & $\begin{array}{c}\text { Marginal association } \\
\chi^{2}\end{array}$ & $\mathrm{p}$ \\
\hline confederate & 1.00 & 0.00 & 1.00 & 0.00 & 1.00 \\
\hline request & 1.00 & 0.00 & 1.00 & 0.00 & 1.00 \\
\hline cheating & 1.00 & 0.25 & 0.62 & 0.25 & 0.62 \\
\hline confederate*request & 1.00 & 0.06 & 0.81 & 0.00 & 1.00 \\
\hline confederate*cheating & 1.00 & 12.79 & 0.01 & 12.73 & 0.01 \\
\hline request*cheating & 1.00 & 0.31 & 0.58 & 0.25 & 0.62 \\
\hline
\end{tabular}

Table 2. Participants by presence or absence of a confederate

\begin{tabular}{|c|c|c|c|}
\hline & Experimenter's confederate present & Experimenter's confederate absent & $\sum$ \\
\hline Cheating & 21 & 7 & 28 \\
\hline No cheating & 9 & 23 & 32 \\
\hline$\Sigma$ & 30 & 30 & 60 \\
\hline
\end{tabular}


Table 3. Differences in the level of self-esteem and attitudes towards disloyalty between cheaters and non-cheaters

\begin{tabular}{|c|c|c|c|c|c|c|}
\hline & \multicolumn{2}{|c|}{ No cheating } & \multicolumn{2}{c|}{ Cheating } & \multirow{2}{*}{ F } & p \\
\hline & $\mathrm{M}$ & $\mathrm{sd}$ & $\mathrm{M}$ & $\mathrm{sd}$ & & \multirow{2}{*}{0.04} \\
\hline Self-esteem & 28.41 & 4.12 & 26.18 & 4.30 & 4.19 & 0.00 \\
\hline Loyalty as a value & 4.52 & 0.53 & 4.13 & 0.49 & 9.19 & 0.07 \\
\hline $\begin{array}{c}\text { Justifications for } \\
\text { disloyalty }\end{array}$ & 3.09 & 0.71 & 3.42 & 0.67 & 3.43 & \multirow{2}{*}{. } \\
\hline
\end{tabular}

Table 4. Division into groups by cheating and confederate's presence

\begin{tabular}{|c|c|c|}
\hline & writing with another cheating person present & writing alone \\
\hline Cheating & Group 1 & Group 3 \\
\hline No cheating & Group 2 & Group 4 \\
\hline
\end{tabular}

Table 5. A comparison of self-esteem levels and attitudes towards disloyalty

\begin{tabular}{|c|c|c|c|c|c|c|c|}
\hline & GR. 1[1] & GR. 2[2] & GR. 3[3] & GR. 4[4] & F & p & Tukey's test \\
\hline Self-esteem & 25.14 & 28.56 & 29.29 & 28.35 & 3.28 & 0.03 & {$[1 \neq 2,3,4]$} \\
\hline Loyalty as a value & 4.11 & 4.71 & 4.16 & 4.45 & 3.64 & 0.02 & {$[1 \neq 2,4],[2 \neq 3]$} \\
\hline $\begin{array}{c}\text { Justifications for } \\
\text { disloyalty }\end{array}$ & 3.36 & 2.93 & 3.57 & 3.15 & 1.49 & 0.23 & NEGL. \\
\hline
\end{tabular}

The results reveal differences in the level of self-esteem and in the attitude towards loyalty between cheaters and non-cheaters (Table 3); the result is on the borderline of significance when it comes to the acceptance of disloyalty in some cases and justifying it.

The participants who cheated scored significantly lower on self-esteem than those who did not cheat $(\mathrm{F}=4.19 \mathrm{p}=0.04)$. The participants who did not cheat valued loyalty significantly higher than cheaters $\operatorname{did}(\mathrm{F}=9.19 \mathrm{p}=0.01)$. Those individuals who cheated more often justified disloyalty.

Next, in order to perform other analyses, participants were divided into four groups: Group 1 was those who cheated in the presence of the experimenter's confederate; Group 2 was those who did not cheat in the confederate's presence; Group 3 was those who cheated in the confederate's absence; finally, Group 4 was those who did not cheat in the confederate's absence (Table 4).

It was checked whether the level of self-esteem and the attitude towards disloyalty determine cheating. In order to verify the hypotheses advanced, analysis of variance (ANOVA) was performed.

Significant differences were found as regards self-esteem $(\mathrm{F}=3.28$ at $\mathrm{p}=0.03)$ and value preference $(\mathrm{F}=3.64$ at $\mathrm{p}=$ $0.02)$. No differences were found between groups as regards the belief that disloyalty may be justified (Table 5). The post hoc Tukey's test showed that self-esteem was significantly higher in the group of people who cheated in the presence of the experimenter's confederate than in the remaining groups (Table 1 and Figure 1).

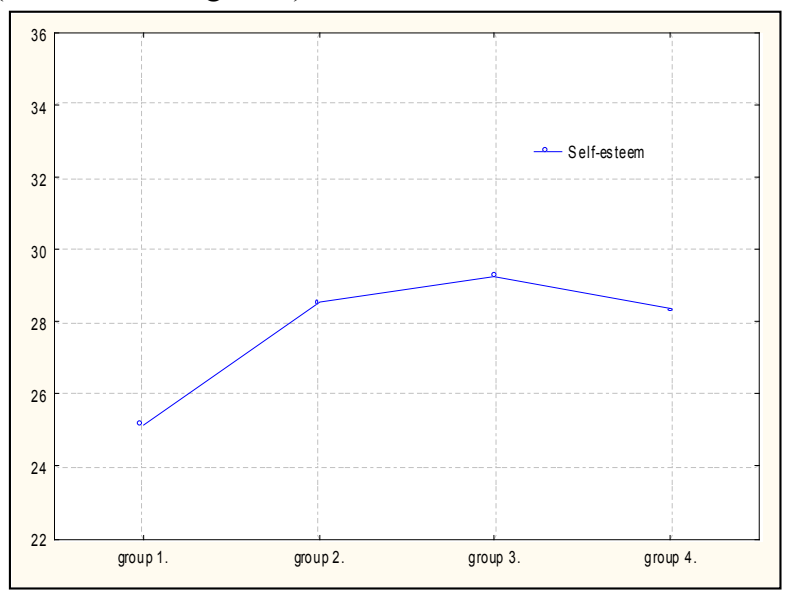

Figure 1. A comparison of self-esteem in individuals who cheated or did not cheat depending on the presence of the experimenter's confederate

Moreover, detailed analyses reveal that the participants who attached the highest value to loyalty were those who did not cheat in the presence of the experimenter's confederate. The individuals who did not cheat (those writing alone as well as those accompanied by another cheating person) valued loyalty higher than individuals cheating in the presence of the experimenter's confederate. Moreover, the individuals who did not cheat in the presence of the confederate valued loyalty higher than those who cheated in the confed- 
erate's absence (Figure 2).

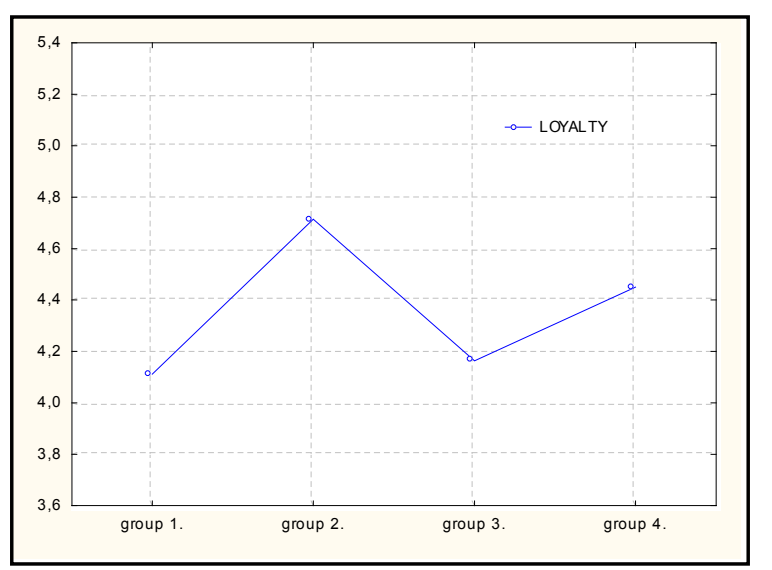

Figure 2. A comparison of the value attached to loyalty by individuals who cheated or did not cheat in the presence or absence of the confederate

\section{Discussion}

Summing up the results of the laboratory experiment, we must say that the decision to cheat is influenced by the presence of another cheating person. No such influence was observed in the case of request not to cheat. Participants were more often dishonest when the experimenter's confederate was doing the same thing than when they were writing alone. This is in keeping with the theory of social influence, which says that we change behavior under the influence of what other people do, think, or feel[21]. It is possible to speak of modeling here, being the imitation of what others do, the change of one's behavior under the influence of the observed behavior of others. In this case, the imitation of behavior was advantageous to the person, since obtaining correct answers from a dictionary improved the test result, which could additionally reinforce and justify the dishonest act[cf. 22, 23]. In the case of the study under discussion, imitation of a cheater by the participant took place (imitation being one of the simplest kinds of social influence - the copying of the behaviors of others in one's own actions). The experimenter's confederates were male as well as female individuals, randomly assigned to test writing. It is possible, then, that the imitation of the cheating person was influenced by the confederate's gender or attractiveness to the participant, which could be a confounding variable. It is also possible here to cite Asch's classic experiment, in which participants changed their attitudes under the influence of judgments form others, thus showing a conformist attitude. Seeing another person cheating, they did the same, adjusting their behavior to the norms adopted by the other person. This may have been caused by the desire to gain the other participant's acceptance and be liked by them, which is called normative influence[cf. 24]. If the experimenter's confederate did not cheat, the participant remained honest as well. The very presence of another person was a strong restraint of dishonest behavior; in this case, the participants followed the pattern of moral behavior. In order to account for the honesty of those who were writing alone, it is possible to refer to Bem's self-perception theory[25]. One of its assumptions is that one learns to recognize his or her states and traits based on the observation of own behavior. We usually have a positive opinion about ourselves, so when somebody asks us to keep an agreement we want to remain loyal in order to avoid cognitive dissonance and to be consistent with what we think of ourselves.

Study results did not confirm the hypothesis concerning the influence of request for honesty on cheating. As regards the already mentioned self-perception theory, we may assume that if a person perceives their behavior as determined by the situation, they do not draw conclusions concerning their traits on the basis of that behavior because they consider the situation to be its cause. This means that the fact of cheating did not necessarily create the "I am disloyal" belief in a given person, since the individual may have attributed their behavior to situational factors. There is also a possibility that the socially accepted norm of keeping agreements was a norm too weakly internalized in cheaters. This is strongly connected with cultural factors; cheating is not stigmatized in Polish schools and has been a rather widespread phenomenon. If, then, the norm in the group is cheating, complying with the request not to cheat would amount to breaking the norm.

Moreover, self-esteem strongly differentiated the decisions on cheating. Cheaters scored higher on self-esteem than non-cheaters. Individuals with high self-esteem felt good and self-confident enough to write the test on their own. This result is consistent with earlier studies, e.g. Aronson and Mettee's[18]. The individuals with the lowest self-esteem were those who cheated in the presence of the experimenter's confederate. Those with high self-esteem feel sure enough of their worth not need to seek its confirmation from others. Individuals with low self-esteem may have sought acceptance from another person, which may be regarded as the already mentioned normative influence. It is also possible here to refer to the study results demonstrating that individuals with high self-esteem undertake more risky actions, whereas individuals with low self-esteem may adopt the attitude of risk avoidance[26]. In the study situation, cheating was burdened with the risk of getting caught in the act, which would expose the participant to shame before the experimenter.

What is more, cheaters attached lower value to loyalty than non-cheaters. The individuals who cheated in the presence of the confederate valued loyalty significantly lower than those who did not cheat in the confederate's presence, which means low self-esteem goes hand in hand with low value attached to loyalty as well as with dishonesty. Such a situation is explained by Ajzen and Fishbein's[27] theory of reasoned action, according to which an attitude, being the content of conscious intention, directly influences the individual's behavior. If, then, one adopts an attitude that allows disloyal behavior (i.e. if we do not value loyalty), it is very likely that in a situation of choice between loyal and disloyal behavior one will choose the second option, since that may be the easier and more profitable option. 
What should be done in order to eliminate dishonesty from schools and colleges? Request and the imposition of norms will certainly not be enough. The presence of other cheaters intensifies such behavior; therefore, the teacher's failure to condemn cheating results in the acceptance of dishonesty. An important element is the change of social norms, for as long as cheating remains an accepted social norm behaviors will be very hard to change. What is also important is the self-esteem in pupils and students; it is essential to reinforce it, since a student who is sure of his or her knowledge will not use crib sheets.

\section{REFERENCES}

[1] Callahan, D. (2004). The cheating culture: Why more Americans are doing wrong to get ahead. New York: Harcourt

[2] McCabe, D. L., Treviño, L. K., \& Butterfield, K. D. (2001). Cheating in academic institutions: A decade of research. Ethics \& Behavior, 11(3), 219-232

[3] Gromkowska-Melosik, A. (2007). Ściagi, plagiaty, fałszywe dyplomy [Crib sheets, plagiarisms, fake diplomas]. Gdańsk: GWP

[4] Garavalia, L., Olson, E., Russell, E., \& Christensen, L. (2007). How do students cheat? In E. M. Anderman \& T. M. Murdock (Eds.), Psychology of academic cheating. Elsevier Academic Press

[5] Newstead, S. E., Franklyn-Stokes, A., \& Armstead, P. (1996). Individual differences in student cheating. Journal of Educational Psychology, 88(2), 229-241

[6] Miller, A. D., Murdock, T. B., Anderman, E. M., \& Poindexter, A. L. (2007). Who are all these cheaters? Characteristics of academically dishonest students. In E. M. Anderman $\&$ T. B. Murdock, The psychology of academic cheating (pp. 9-32). Elsevier Academic Press

[7] Lim, V. K. G., \& See, S. K. B. (2001). Attitudes toward, and intentions to report, academic cheating among students in Singapore. Ethics \& Behavior, 11(3), 261-274

[8] Tas, Y., \& Tekkaya, C. (2010). Personal and contextual factors associated with students' cheating in science. The Journal of Experimental Education, 2010, 78, 440-463

[9] McCabe, D. L., Feghali, T., \& Abdallah, H. (2008). Academic dishonesty in the Middle East: Individual and contextual factors. Research in Higher Education, 9, 451-467

[10] Whiley, B. E. (1998). Factors associated with cheating among college students: A review. Research in Higher Education, 39, 235-274

[11] Finn, K. V., \& Frone, M. R. (2004). Academic performance and cheating: Moderating role of school identification and self-efficacy. The Journal of Educational Research, 97(3), 115-122
[12] De Bruin, G. P., \& Rudnick, H. (2007). Examining the cheats: The role of conscientiousness and excitement seeking in academic dishonesty. Psychological Society of South Africa, $37(1), 153-164$

[13] Marsden, H., Carrol, M., \& Neil, J. T. (2005). Who cheats at university? A self-report study of dishonest academic behaviours in a sample of Australian university situations. Australian Journal of Psychology, 57(1), 1-10

[14] Staats, S., Hupp, J. M., \& Hagley, A. M. (2008). Honesty and heroes: A positive psychology. View of heroism and academic honesty. The Journal of Psychology, 142(4), 357-372

[15] Staats, S., Hupp, J. M., Wallace, H., \& Gresley, J. (2009). Heroes don't cheat: An examination of academic dishonesty and students' views on why professors don't report cheating. Ethics \& Behavior, 19(3), 171-183

[16] Błachnio, A. (2007). Inni będą lojalni wobec ciebie, jeśli ich o to poprosisz [Others will be loyal to you if you ask them for it]. In A. Błachnio \& A. Gózik, Bliżej emocji [Closer to emotions] (pp. 103-115). Lublin: Wydawnictwo KUL

[17] Leary, M. R. (1995). Self-presentation: Impression management and interpersonal behavior. Boulder: Westview

[18] Aronson, E., \& Mettee, D. R. (1968). Dishonest behavior as a function of differential levels of induced self-esteem. Journal of Personality and Social Psychology, 9, 121-127

[19] Błachnio, A. (2005). Psychologiczne determinanty nielojalności w relacjach interpersonalnych. Badania empiryczne [The psychological determinants of disloyalty in interpersonal relations. Empirical studies]. Lublin: unpublished doctoral dissertation

[20] Łaguna, M., Lachowicz-Tabaczek, K., \& Dzwonkowska, I. (2007). Skala samooceny SES Morrisa Rosenberga - polska adaptacja metody [Morris Rosenberg's self-esteem scale SES - a Polish adaptation of the method]. Psychologia Społeczna, 164-176, 2(4)

[21] Latané, B. (1981). The psychology of social impact. American Psychologist, 36, 343-356

[22] Bandura, A. (1977). Social Learning Theory. Englewood Cliffs, NJ: Prentice Hall

[23] Zimbardo, P. G., \& Leippe, M. R. (2004). Psychologia zmiany postaw i wpływu społecznego [The psychology of attitude change and social influence]. Poznań: Wydawnictwo Zysk i S-ka

[24] Grzelak, J. Ł., \& Nowak, A. (2000). Wpływ społeczny [Social influence]. In J. Strelau (Ed.). Psychologia. Podręcznik akademicki [Psychology. An academic textbook], vol. 3, (pp. 187-204). Gdańsk: GWP

[25] Bem, D. J. (1972). Self-perception theory. Advances in Experimental Social Psychology, 6, 1-62

[26] Baumeister, R., Smart, L., \& Boden, J. (1996). Relation of threatened egotism to violence and aggression: The dark side of high self-esteem. Psychological Review, 103, 5-33

[27] Ajzen, I., \& Fishbein, M. (1980). Understanding attitudes and predicting social behavior. Englewood Cliffis, NJ: Prentice Hall 